NBER WORKING PAPER SERIES

\title{
ARE MACROECONOMIC FORECASTS INFORMATIVE? COINTEGRATION EVIDENCE FROM THE ASA-NBER SURVEYS
}

\author{
Yin-Wong Cheung \\ Menzie D. Chinn \\ Working Paper 6926 \\ http://www.nber.org/papers/w6926
NATIONAL BUREAU OF ECONOMIC RESEARCH
1050 Massachusetts Avenue
Cambridge, MA 02138
February 1999

We thank Hui Miao for research assistance. This research was supported by faculty research funds granted by the Academic Senate of the University of California, Santa Cruz. All remaining errors are solely the authors' responsibility. The views expressed here are those of the author and do not reflect those of the National Bureau of Economic Research.

- 1999 by Yin-Wong Cheung and Menzie D. Chinn. All rights reserved. Short sections of text, not to exceed two paragraphs, may be quoted without explicit permission provided that full credit, including ${ }^{(0)}$ notice, is given to the source. 
Are Macroeconomic Forecasts Informative?

Cointegration Evidence from the ASA-NBER Surveys

Yin-Wong Cheung and Menzie D. Chinn

NBER Working Paper No. 6926

February 1999

JEL No. E17, C53, C42

\section{ABSTRACT}

We examine the properties of the ASA-NBER forecasts for several US macroeconomic variables, specifically: (i) are the actual and forecast series integrated of the same order; (ii) are they cointegrated, and; (iii) is the cointegrating vector consistent with long run unitary elasticity of expectations with respect to the actual series. We also examine whether forecasts respond to error correction terms. Tests are applied to both final and preliminary versions of the data. We find that the Treasury bill rate, housing starts, industrial production, inflation and their forecasts are trend stationary. The corporate bond rate, GNP, the GNP deflator, unemployment and their forecasts are difference stationary. About half of the these pairs are cointegrated, with the unitary elasticity restriction seldom rejected. Similar results are obtained when using the originally-reported data.

Yin-Wong Cheung

Department of Economics

Social Sciences I

University of California

Santa Cruz, CA 95064

cheung@cats.ucsc.edu
Menzie D. Chinn

Department of Economics

Social Sciences I

University of California

Santa Cruz, CA 95064

and NBER

chinn@cats.ucsc.edu 


\section{INTRODUCTION}

A large industry involved in the forecasting of key macroeconomic variables, such as gross national product, inflation rates, interest rates and industrial production, has arisen over the past three decades. These forecasts, produced by independent financial analysts, bank research departments, and the like, more often than not incorporate subjective judgements. Consequently, academic economists have typically looked askance at such forecasts, and have relied instead on time series and other econometric methods to make conditional forecasts. Yet given the weight place by professional traders and policy makers on such judgement-based forecasts, it is important to know exactly what information is contained within these forecasts.

In this paper, we assess a hitherto neglected aspect of the time series properties of the ASA-NBER forecasts. In particular, we examine whether forecasts exhibit a weak form of rationality, termed "consistency", which fulfills the following conditions: (i) the actual and forecast series are integrated of the same order; (ii) they are cointegrated, and; (iii) the cointegrating vector is consistent with long run unitary elasticity of expectations with respect to the actual series. Each of these conditions is increasingly more stringent than the one preceding it. Clearly, if one series in a pair is an integrated process and the other is a trend stationary one, then over time such series must drift infinitely far apart. If condition (i) is fulfilled, but condition (ii) is not, then once again these two series will drift apart. Finally, the forecast and the actual series could be cointegrated, but the long-run elasticity of the forecast with respect to the exchange rate could be different than unity. In the absence of measurement error, no sensible forecast should behave thus, since it implies that the forecast does not move one for one with the actual series, even in the long 
run. ${ }^{1}$

Typically, when examining forecast accuracy researchers examine the mean, variance and serial correlation properties of the forecast errors. The issues of integration and cointegration are rarely addressed (with exceptions cited below). Yet these issues can be very important, as pointed out in Clements and Hendry $(1993,1994)$. They observe that the root mean squared prediction error (RMSE) yields different forecast rankings depending upon whether the evaluation is conducted in levels or differences. Bonham and Cohen (1995), in a slightly different context, also argue that ignoring aspects of stationarity may lead to improper inferences regarding the rationality of forecasts. (Moreover, the usual criteria ignores distinctions of permanent versus transitory movements which are critical to characterizations of macro time series.) We also examine whether forecasts respond to disequilibria, such as estimated error correction terms, or prediction errors.

We conduct this examination in the following manner. In section 2, we review the literature and discuss the characteristics of the survey forecast data used in this study. In section 3 , the tests for integration, cointegration, and for coefficient restrictions are described. Section 4 reports the empirical results of these tests using the final (revised) series. Section 5 discusses the interpretation of error correction specifications for forecasts (implied by cointegration), and the empirical results. Section 6 repeats the exercise for the initially reported (unrevised) series. Section 7 concludes.

${ }^{1}$ The usage of "consistency" here is different from that in econometrics, where it denotes convergence in probability, a concept that involves the property of the estimator when the sample size approaches infinity. A companion paper to this one, involving structural exchange rate forecasts, is Cheung and Chinn (1998). 


\section{STUDIES OF FORECAST RATIONALITY}

\subsection{Previous Literature}

Survey data are generally viewed with suspicion by economists, even more so as the rational expectations approach to macroeconomics has come to dominate economic discourse. The skepticism is borne of desire to infer preferences from actions, rather than statements. Unfortunately, as most glaringly made obvious by the exchange rate literature, rational expectations measures of expectations have their own limitations (see Froot and Thaler, 1990). Consequently, macroeconomists have long resorted to various survey measures such as the Livingstone survey of inflationary expectations. Several recent studies have found that survey data do contain useful information about future events. ${ }^{2}$ Typically, in assessing the rationality of these survey-based forecasts, the usual metrics have been used -- mean error, root mean squared error, and mean absolute error. A good example of this approach is Zarnowitz and Braun (1993).

Recently, Aggarwal, Mohanty and Song (1995) have assessed the unbiasedness and integration and cointegration characteristics of macroeconomic data and their respective forecasts, published by Money Market Services (MMS). However, they -- like Liu and Maddala (1992) in their examination of MMS exchange rate forecasts -- impose a unitary elasticity of forecasts with respect to actual series; in contrast, our modeling approach is more flexible, allowing for cointegration without necessarily imposing these constraints. Hence we can test for whether the restriction is rejected or not. ${ }^{3}$ Moreover, all of these previous studies use inefficient tests for either

\footnotetext{
${ }^{2}$ See for instance Dokko and Edelstein, 1989; Englander and Stone, 1989 and Keane and Runkle, 1990.

3 Other papers directly addressing this issue of integration and cointegration include Fischer (1989) for M1, and Lahiri and Chun (1989) for GNP, the price deflator and the unemployment
} 
integration or cointegration, or for both. In contrast, we apply more powerful unit root tests corrected for small sample effects, and the Johansen and Juselius (1990) multivariate cointegration testing procedure which is more efficient than other testing procedures.

In assessing the forecast characteristics, we also carefully distinguish between the initial unrevised series, and the subsequently revised, final series. Presumably, the forecasters are attempting to predict the former. Hence, comparisons of forecasts and actual revised series, as in many previous studies, is unlikely to provide an accurate picture of forecast rationality.

\subsection{The ASA-NBER Survey of Forecasters}

Since 1968, the American Statistical Association (ASA) and the National Bureau of Economic Research (NBER) have jointly undertaken a survey of macroeconomic forecasters. Over time, the series surveyed as well as the respondents, have varied. However, taken together, these forecasts comprise the most extensive and longest uninterrupted set of series available. A detailed discussion of the coverage and characteristics of the ASA-NBER forecast surveys is provided by Zarnowitz and Braun (1993).

The ASA-NBER database includes forecasts of industrial production, the GNP deflator, real GNP, housing starts, the CPI inflation rate, the 3 month treasury bill rate, the yield on corporate bonds, nominal after tax corporate profits, and the rate of unemployment.

We obtained the median forecasts and the actual unrevised series from CITIBASE. The actual revised, or official, series are also retrieved from the same source. In general, the data begin in 1970 at the earliest, and in 1981 for several of the series. The data appendix contains detailed

rate. In their paper, Lahiri and Chun test for cointegration with unitary elasticity restrictions using a less efficient ADF test on a constructed regressor. 
descriptions of the series used. ${ }^{4}$

\section{METHODOLOGY}

\subsection{Unit Root Test}

For a time series $\left\{\mathrm{y}_{\mathrm{t}}\right\}_{\mathrm{t}=1, \ldots, \mathrm{T}}$, the ADF test for a unit root is based on the regression

$$
\Delta y_{t}=c+\mu t+\pi y_{t-1}+\sum_{j=1}^{k} \gamma_{j} \Delta y_{t-j}+u_{t}
$$

The following procedure is used to determine the lag order parameter k. First, the Akaike Information Criterion and the Schwartz Bayesian Information Criterion (AIC and SBC respectively) are used to select the lag order among specifications $k=1, \ldots, 6$. This is in accord with Hall's (1994) finding that such a lag selection process can improve both the size and power of the ADF test. Then, residuals from the selected specification are tested for serial correlation. If significant serial correlation is detected, the lag length is increased until the model passes the residual test. In many cases the two criteria yield similar inferences and so in order to conserve space, we only report the results based on the AIC.

The unit root null hypothesis is rejected if $\pi$ estimate is significantly less than zero. Since the usual t-statistic for $\pi$ does not have a standard $\mathrm{t}$-distribution, finite sample critical values that adjusted for both sample size and lag order effects are used to determine the significance of the ADF statistic (see Cheung and Lai (1995) for details).

\subsection{Testing for Cointegration}

\footnotetext{
${ }^{4}$ Two of the unrevised series, GNP and industrial production index, have to be re-based to express them in a constant numeraire (either in $1987 \$$, or in a common base year). The series are re-based by splicing them using data from the Survey of Current Business. This issue does not arise in previous studies which examine percentage changes in these series.
} 
Testing for cointegration proceeds in the following manner. Consider in general an $\mathrm{m} \times 1$ vector $\mathbf{x}_{\mathrm{t}}$ of $\mathrm{I}(1)$ variables and its $\operatorname{VAR}(\mathrm{p})$ representation:

$$
\begin{gathered}
\Delta x_{t}=\mu+\Gamma_{1} \Delta x_{t-1}+\Gamma_{2} \Delta x_{t-2}+\ldots \Gamma_{p-1} \Delta x_{t-p+1}+\Pi x_{t-p}+u \\
\Pi=\alpha \beta^{\prime}
\end{gathered}
$$

where $\Gamma_{1}, \Gamma_{2}, \ldots \Gamma_{\mathrm{p}-1}, \Pi$ are $\mathrm{m} \times \mathrm{m}$ matrices of unknown parameters. $\alpha$ and $\beta$ are $\mathrm{m} \times \mathrm{r}$ matrices, representing the rate of reversion and cointegrating parameters, respectively. See Johansen (1991) for a more detailed account of this cointegration methodology.

Johansen proposes two tests for inferring the number of cointegrating vectors. The trace statistic is used for testing the null hypothesis of at most $r$ cointegrating vectors against the alternative of $m$ cointegrating vectors. The maximal eigenvalue statistic is used in testing the null hypothesis of r-1 against r cointegrating vectors. According to our definition of "consistency", forecasts should be cointegrated with the actual series. Failing this, forecasts could drift infinitely far away from the actual series.

A stronger requirement for the consistency of a forecast is that the coefficients in the cointegrating vector are (-1 1). We find it plausible that the estimated cointegrating vector may differ from that posited in previous studies. For instance, if the median survey response measures the true market expectation with error, then the estimated cointegrating vector may very well be different than $(-11)$.

A simple example can illustrate this point. Let $y$ be the actual variable, $y^{\mathrm{e}}$ be the unobserved market expectation, and $\mathrm{y}^{\mathrm{f}}$ be the median survey response. If market expectations are rational: 


$$
y=y^{e}+u \quad u \sim \operatorname{iid}\left(0, \sigma^{2}\right)
$$

Further, suppose the median survey measures the market expectation with error of a particular form:

$$
y^{f}=\phi_{0}+\phi_{1} y^{e} \quad \phi_{1} \neq 1
$$

Then re-writing one finds that the equation estimated with survey data is:

$$
\begin{aligned}
y & =\frac{\phi_{0}}{\phi_{1}}+\frac{1}{\phi_{1}} y^{f}+u \\
& =b_{0}+b_{1} y^{f}+u
\end{aligned}
$$

That is, the elasticity of the actual with respect to the median survey response can deviate from unity.

Following Johansen (1991) and Johansen and Juselius (1990), the hypothesis of a linear constraint on the cointegrating vector can be expressed as:

$$
H_{G}: \beta=G B
$$

where $\mathrm{G}$ is a known $\mathrm{m} \times \mathrm{r}_{0}$ matrix of full rank $\mathrm{r}_{0}$, and $\mathrm{B}$ is $\mathrm{a} \mathrm{r}_{0} \times \mathrm{r}$ matrix of unknown parameters ( $m \geq r_{0} \geq r$ ). If $r_{0}=r$, the cointegrating space is fully specified. If $r_{0}=m$, then no restriction is imposed on $\beta$. Note that $G$ is the matrix that defines the coefficient restriction. In terms of (6), the unitary elasticity restriction is described by $(1-1)^{\prime}$, so $r_{0}=1$ in this case. In the following section, the Johansen (1991) likelihood ratio test statistic will be used to evaluate $\mathrm{H}_{\mathrm{G}}$. 


\section{Estimation Results}

The unit root test results are presented in Table 1 . The ADF $\tau_{t}$ statistic is reported, as well as the order of lags used in the regression. In five of nine cases, the reported series (what is termed the "actual revised") fail to reject the unit root null using the 5\% marginal significance level (MSL). The exceptions are the three month Treasury Bill interest rate, housing starts, industrial production and the CPI inflation rate. Reassuringly, the results for the initially reported counterparts of these variables are in agreement, with the exception of housing starts and industrial production. According to the originally reported data (hereafter "actual unrevised"), housing starts and industrial production fail to reject the unit root null.

For the real GNP series, the forecasts at all horizons match the order of integration for the actual revised series. The same is true for the GNP deflator, after-tax corporate profits, and the unemployment rate. These forecasts therefore fulfill the first condition of consistency.

For housing starts and industrial production, slightly less than half of the forecasts are of the same order of integration as the actual revised. Note that in both of these series' cases, comparing against the actual unrevised series would cause a discrepancy since those series appear to be trend stationary. In fact, it is somewhat troubling from a practical standpoint that the actual revised and actual unrevised series do not appear to be of the same order of integration.

The two interest rates present a different pattern of results. For the T-Bill rate, all the series appear to be trend stationary with the exception of 1- and 3-quarter ahead forecasts. The actual corporate bond rate appears to contain a unit root. However the 4-quarter ahead forecasts appear trend stationary.

To summarize the results, for the revised T-bill rate, GNP, GNP deflator, housing starts, 
industrial production, corporate profits, unemployment and CPI inflation series and their respective forecasts, the implied orders of integration are consistent. The same holds true for the unrevised series, except housing starts and industrial production drop from the list. Of these, in both sets, the GNP, GNP deflator, corporate profits and unemployment rate appear to be integrated of order 1 .

Table 2 contains the Johansen test results. Evidence of cointegration is obtained for the corporate bond rate at all relevant horizons, for the GNP deflator at the 1-quarter horizon, for GNP at the 4-quarter horizon and the unemployment rate at all horizons except the 4-quarter. A mixed finding is obtained for GNP at the 3-quarter horizon; the maximal eigenvalue statistic indicates 0 cointegrating vectors, while the trace statistic indicates 1 vector. Since the trace statistic appears to be more robust to non-Normal errors, in such cases we will interpret this as a finding of cointegration. Consequently, we find 9 cases of cointegration out of a possible 19 cases. While similar results for unemployment were obtained by Aggarwal et al. (1995), we are unaware of any similar findings for the other series.

Our definition of consistency requires not only that the series do not drift infinitely far apart, but also that the cointegrating vector is $(-11)$. We find that this requirement holds for all those cases where a single cointegrating vector is found, with the sole exception of the 1-quarter horizon GNP deflator.

\section{Single-Equation Error Correction Specifications}

The Engle-Granger (1987) representation theorem indicates that any cointegrated system can be rewritten as an error correction system. Assuming the moving average process can be approximated by a finite autoregression of the first differences, one obtains in the context of our 
bivariate system:

$$
\begin{aligned}
& \Delta x_{t}^{f}=\mu_{1}+\sum_{i=1}^{p} \gamma_{1 i} \Delta x_{t-i}+\sum_{j=1}^{q} \gamma_{2 j} \Delta x_{t-j}^{f}+\alpha_{1}\left(\beta_{1} x+\beta_{2} x^{f}\right)_{t-1}+u_{1 t} \\
& \Delta x_{t}=\mu_{2}+\sum_{k=1}^{r} \gamma_{1 k} \Delta x_{t-k}+\sum_{m=1}^{s} \gamma_{2 m} \Delta x_{t-m}^{f}+\alpha_{2}\left(\beta_{1} x+\beta_{2} x^{f}\right)_{t-1}+u_{2 t}
\end{aligned}
$$

We are primarily interested in whether the forecast series responds to the actual revised series. The results of estimating equations 20 and 21 are summarized in Panels A and B, respectively, of Table 3. The series for which this question is relevant are the corporate bond rate (1- to 3quarter), GNP (3-, 4-quarter), and the unemployment rate (1- to 3-quarter). The corporate bond rate, GNP and the unemployment rate forecasts respond to disequilibria, as measured by the cointegrating error, in a statistically significant manner. While the actual series also respond to these disequilibria, the proportion of variation explained is much lower than for the corresponding forecast regressions.

We also estimated error correction models with the cointegrating vector of (-1 1) imposed. The results exhibit the same pattern as those using the estimated coefficients (which is unsurprising given that the unitary elasticity condition is seldom rejected). These results are available from the authors upon request.

\section{Results Using Unrevised Data}

There has been some discussion of whether forecasters forecast the underlying variable of interest, or the preliminary estimate. This ambivalence suggests that we evaluate the sensitivity of our findings to whether the final (revised), or the initial (unrevised) series are used. Certainly, 
some sensitivity is to be expected, most importantly because the order of integration implied by the univariate tests differs between the revised and unrevised series in two instances: housing starts, industrial production (see Table 1). In fact, the latter pair fails to exhibit evidence of cointegration, while the former does.

The results of running the cointegration tests are presented in Table 4. Overall, the cointegration results do not appear to be substantially different than before. However, to the extent that they differ, some pairs exhibit more evidence of a single cointegrating vector (corporate profits and GNP deflator), and others less (unemployment). Furthermore, housing starts are cointegrated while industrial production is not. Forecasters appear to be forecasting the unrevised series (which are published soon after these forecasts) slightly more than they are the revised series. This pattern of results is consonant with those obtained by Keane and Runkle (1990).

There are two ambiguous cases which merit additional discussion. The tests indicate that the GNP 1-quarter ahead forecast and the actual series appear to each be stationary. Closer inspection of the test statistics indicate that they are both borderline significant for 2 cointegrating vectors. A similar situation applies to the trace statistic for the 3-quarter ahead GNP deflator and the actual series. We interpret these cases as cases of cointegration with one cointegrating vector.

The restriction on the cointegrating vector is rejected at the 5\% MSL in only five cases where cointegration is found (housing starts at 2-quarter horizon, GNP at 4-quarter horizon, and the corporate bond rate at all relevant horizons) out of 15 . To sum up, out of 22 pairs of forecasts and actual series, 15 exhibit cointegration; of these, 10 pass the coefficient restriction test.

Estimation of the relevant ECMs is reported in Table 5. The results indicate that of the 
cointegrated pairs that pass the unitary-elasticity restriction, all except the 1- and 2-quarter ahead GNP deflator, 1- and 2-quarter ahead corporate profits and the 1-quarter ahead housing starts exhibit statistically significant response of the forecasts to the error correction term.

Thus far, we have examined the consistency aspects of the survey forecasts. A related issue is the relative importance of short and long run factors in determining the response of forecasts. This question can be posed explicitly in the following manner. Taking equation (20), we adduce to the long run factors the difference in adjusted $\mathrm{R}^{21} \mathrm{~s}$ between the constrained specification (omitting the error correction term) and the unconstrained specifications. Table 6 reports the results using unrevised data, and the same lag structure as reported in Table 5. The examination of this question using unrevised data is most appropriate because the forecasts will be responding to disequilibria defined using the actually observed data. The actual revised data are not available to the forecasters until months, and perhaps even years, after the forecasts are made.

The results indicate that in exactly the case where the rate of reversion is the most pronounced, namely the corporate bond rate, the imposition of the long run restriction via the error correction term adds the most, raising the adjusted $\mathrm{R}^{2}$ by between 0.61 and 0.75 . For the other variables, the difference is much less marked. However, as one would expect, the additional information imparted by the error correction term increases with the forecast horizon. The improvement rises from 0.02 to 0.10 as the forecast horizon for GNP increases from 1 quarter to 4 quarters ahead. Similarly, the GNP deflator improvement rises monotonically from 0.00 to 0.05 . Presumably, the importance of the error correction term would increase with even longer forecast horizon. 
While the improvement in explained variation is sometimes modest, comparison to results using other survey forecasts may be place these results in perspective. For instance Chinn and Frankel (1994) find that while exchange rate expectations do respond to error correction terms (defined as forecast errors), the degree of statistical significance was variable, even at the 12 month horizon. ${ }^{5}$ This suggests that, by comparison to other survey measures, there is substantial long run information contained in the ASA-NBER forecasts.

\section{Concluding Remarks}

This paper has applied a different, and less stringent, criteria for rationality to the ASANBER macroeconomic forecasts. The findings of these tests are summarized in Table 7. Each " entry denotes fulfillment of a single criterion. In Panel A (the revised series), 30 out of 36 cases fulfill the requirement that forecast and actual possess the same order of integration. Eleven of these cases involve trend stationary pairs, and are not further investigated. Of the 19 remaining pairs, eight are definitely cointegrated; another pair is probably cointegrated with the trace statistic indicating rejection of the null hypothesis of zero cointegrating vectors. Of the nine cointegrated pairs, eight fulfill the requirement of unitary elasticity. The cases of consistency appear largely series-specific -- the corporate bond rate and the unemployment rate account for most of the cases.

Surprisingly, the linkage between forecasts and unrevised actual series is not unambiguously stronger. Twenty-eight of 36 cases fulfill the first requirement. Six of these cases are trend stationary pairs. Of the 22 integrated pairs, 11 are clearly cointegrated, while an

\footnotetext{
${ }^{5}$ See equation (11) in Chinn and Frankel (1994), which can be rewritten as an error correction model. The parameter estimates are reported in Table 4.2 of that paper.
} 
additional four pairs are probably cointegrated. Ten out of 22 series fulfill the third criterion (as opposed to eight out of 19 for the revised series). Hence, while there appears to be greater evidence of cointegration for the unrevised series, there is only slightly greater evidence of consistency.

To sum up the specific findings, the final versions of the industrial production series and the inflation rate, and most of their respective forecasts appear to be trend stationary. The Treasury bill rate and housing starts are mixed. The corporate bond rate, GNP, the GNP deflator, after tax corporate profits, unemployment and most of their respective forecasts appear to be difference stationary. Almost half of the unit root series appear to be cointegrated with their respective forecasts. In only one relevant case is the unitary elasticity restriction rejected. The forecasts appear to behave in a reasonable manner; they respond to disequilibria (defined by the estimated cointegrating vector). Moreover, this finding is robust to the use of an imposed (-1 1) cointegrating vector, rather than an estimated one.

Similar results are obtained when using the originally reported data (actual unrevised), In accord with priors there is more evidence of cointegration. However, there is only slightly evidence to support unitary elasticity of expectations.

We conclude, in line with much recent research, that survey data do fulfill some weak conditions for rationality, although seldom are all three criteria met. 


\section{REFERENCES}

Aggarwal, Raj, Sunil Mohanty and Frank Song, 1995, "Are Survey Forecasts of Macroeconomic Variables Rational?" Journal of Business 68(1) (January), 99-119.

Bonham, Carl and Richard Cohen, 1995, "Testing the Rationality of Price Forecasts: Comment," American Economic Review 85(1) (March), 284-289.

Bonham, Carl and Douglas Dacy, 1991, "In Search of a 'Strictly Rational' Forecast," Review of Economics and Statistics 73(2): 245-253.

Cheung, Yin-Wong and Menzie Chinn, 1998, "Integration, Cointegration, and the Forecast Consistency of Structural Exchange Rate Models," Journal of International Money and Finance 17(5): 813-830. Also NBER Working Paper \#5943.

Cheung, Yin-Wong and Kon S. Lai, 1995, "Lag Order and Critical Values of the Augmented Dickey-Fuller Test," Journal of Business and Economic Statistics 13(3): 277-280.

Cheung, Yin-Wong and Kon. S. Lai, 1993, "Finite-Sample Sizes of Johansen's Likelihood Ratio Tests for Cointegration," Oxford Bulletin of Economics and Statistics 55(3): 313-328

Chinn, Menzie and Jeffrey Frankel, 1994, "More Survey Data on Exchange Rate Expectations: More Currencies, More Horizons, More Tests," Paper presented at the AEA Winter Meetings, January, 1995, Washington D.C.

Dokko, Yoon and Robert H. Edelstein, 1989, "How Well Do Economists Forecast Stock Market Prices? A Study of the Livingstone Surveys." American Economic Review 79(4) (September), 865-871.

Dominguez, Kathryn, 1986, "Are Foreign Exchange Forecasts Rational? New Evidence from Survey Data?" Economic Letters 21, 277-82.

Englander, A. Steven and Gary Stone, 1989, "Inflation Expectations Surveys as Predictors of Inflation and Behavior in Financial and Labor Markets," Federal Reserve Bank of New York Quarterly Review 14 (Autumn), 20-32.

Fischer, Andreas M., 1989, "Unit Roots and Survey Data," Oxford Bulletin of Economics and Statistics 51: 451-463.

Hall, Alastair, 1994, "Testing for a Unit Root in Time Series with Pretest Data based Model Selection," Journal of Business and Economic Statistics 12: 461-470.

Johansen, Soren, 1988, "Statistical Analysis of Cointegrating Vectors." Journal of Economic 
Dynamics and Control. 12: 231-54.

Johansen, Soren, and Katerina Juselius, 1990, "Maximum Likelihood Estimation and Inference on Cointegration - With Applications to the Demand for Money." Oxford Bulletin of Economics and Statistics. 52: 169-210.

Keane, Michael P. and David E. Runkle, 1990, "Testing the Rationality of Price Forecasts: New Evidence from Panel Data," American Economic Review 80(4) (September), 714-735.

Lahiri, Kajal and T.S. Chun, 1989, "Some Tests for Unbiasedness in the Long-Run Using Survey Data," International Economic Journal 3(2) (Summer): 27-42.

Liu, Peter, and G.S. Maddala, 1992, "Rationality of Survey Data and Tests for Market Efficiency in the Foreign Exchange Markets," Journal of International Money and Finance 11: 366-381.

Zarnowitz, Victor and Phillip Braun, 1993, "Twenty-Two Years of the NBER-ASA Quarterly Economic Outlook Surveys: Aspects and Comparisons of Forecasting Performance," in James Stock and Mark Watson (editors) Business Cycles, Indicators and Forecasting (Chicago: University of Chicago Press): 11-84. 


\section{DATA APPENDIX:}

SOURCE: $\quad$ American Statistical Association and National Bureau of Economic Research.

DOCUMENT: $\quad$ Business Outlook Survey

RANGE: $\quad$ Actual figure unrevised, 1977-present, unless indicated. Forecasts include current unrevised and 1-4 quarter ahead forecasts

FREQUENCY: Quarterly

DATA VERSION: CITIBASE (Citibank economic database) 1992

VARIABLES:

New High-grade Corporate Bond Yield (Percent per Annum) From 1982Q2 to 1993Q3, Quarterly Data.

Treasury Bill Rate (3-Month) (Percent per Annum) From 1982Q2 to 1993Q3, Quarterly Data.

Gross National Product (in billions of 1987 dollars ) From 1970Q1 to 1992Q2, Quarterly Data. $1 /$

GNP Implicit Price Deflator (1987=100) From 1970Q1 to 1992Q2, Quarterly Data.

Corporate Profits After Taxes (Billions of \$) From 1977Q1 to 1993Q3, Quarterly Data.

Gross Industrial Production (1987=100) From 1970Q1 to 93Q3, Quarterly Data. 1/

New Private Housing Starts (Annual Rate, Millions) From 1970Q1 to 1993Q3, Quarterly Data. 2 /

Consumer Price Index inflation rate (Percent Change) From 1982Q2 to 1993Q3, Quarterly Data.

Unemployment Rate (Percent) From 1970-Q1 to 93-Q3, Quarterly Data.

Notes:

1/ GNP and Industrial Production are re-indexed according to "Current Business Survey".

2/ Housing Starts, Consumer Price Index, Unemployment Rate are originally monthly data, and are converted to quarterly data by taking the average of monthly data. 
TABLE 1

Augmented Dickey-Fuller Test Results

\begin{tabular}{|c|c|c|c|c|c|c|}
\hline \multicolumn{2}{|c|}{$\begin{array}{l}\text { Variables } \\
\qquad \begin{array}{l}\text { Actual } \\
\text { Unrev'd }\end{array}\end{array}$} & 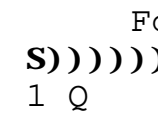 & $\begin{array}{l}\text { recast HC } \\
\text { )) ) ) ) ) } \\
2 Q\end{array}$ & $\begin{array}{l}\text { rizon } \\
())()) ! \\
3 Q\end{array}$ & $\begin{array}{c}\text { ) ) ) Q } \\
4 \mathrm{Q}\end{array}$ & $\begin{array}{l}\text { Actual } \\
\text { Revisec }\end{array}$ \\
\hline ) (5) ()() () () () () () () & )()) () ) () & )) ()) () & ()) () ) ) () & )) ) () ) & )) () () () & )) Q \\
\hline $\begin{array}{l}\text { Corp. Bond Rate } \\
\text { Lag }\end{array}$ & $\begin{array}{l}-3.11 \\
1\end{array}$ & $\begin{array}{l}-2.77 \\
1\end{array}$ & $\begin{array}{l}-0.88 \\
1\end{array}$ & $\begin{array}{l}-3.26 \\
1\end{array}$ & $\begin{array}{l}-3.54 * \\
1\end{array}$ & $\begin{array}{l}-3.06 \\
1\end{array}$ \\
\hline $\begin{array}{l}\text { Treasury Bill Rate } \\
\text { Lag }\end{array}$ & $\begin{array}{l}-3.58 * \\
2\end{array}$ & $\begin{array}{l}-3.48 \\
1\end{array}$ & $-3.75 *$ & $\begin{array}{l}-3 \cdot 44 \\
4\end{array}$ & $\begin{array}{l}-3.47 \star \\
5\end{array}$ & $-3.45 \star$ \\
\hline GNP & -0.90 & 1.01 & 0.55 & 0.50 & 0.23 & 0.52 \\
\hline Lag & 2 & 3 & 3 & 3 & 2 & 2 \\
\hline $\begin{array}{l}\text { GNP Deflator } \\
\text { Lag }\end{array}$ & $\begin{array}{l}-2 \cdot 19 \\
1\end{array}$ & $\begin{array}{l}-0.84 \\
4\end{array}$ & $\begin{array}{l}-0.36 \\
3\end{array}$ & $\begin{array}{l}-0.49 \\
3\end{array}$ & $\begin{array}{l}-0.50 \\
3\end{array}$ & $\begin{array}{l}-0.76 \\
3\end{array}$ \\
\hline $\begin{array}{l}\text { Corp. profits } \\
\text { Lag }\end{array}$ & $\begin{array}{l}-2.07 \\
1\end{array}$ & $-1 \cdot 98$ & $\begin{array}{c}-1 \cdot 74 \\
3\end{array}$ & $\begin{array}{l}-1 \cdot 94 \\
2\end{array}$ & $\begin{array}{c}-1 \cdot 77 \\
2\end{array}$ & $\begin{array}{l}-2.44 \\
2\end{array}$ \\
\hline $\begin{array}{l}\text { Housing Starts } \\
\text { Lag }\end{array}$ & $\begin{array}{l}-2.44 \\
2\end{array}$ & $\begin{array}{l}-3.36 \\
5\end{array}$ & $\begin{array}{l}-3.16 \\
2\end{array}$ & $\begin{array}{l}-3.79 * \\
5\end{array}$ & $\begin{array}{l}-3.80 * \\
6\end{array}$ & $\begin{array}{l}-4.07 \star \\
6\end{array}$ \\
\hline $\begin{array}{l}\text { Industrial Prod. } \\
\text { Lag }\end{array}$ & $\begin{array}{l}-2 \cdot 91 \\
2\end{array}$ & $\begin{array}{l}-4 \cdot 30 * \\
6\end{array}$ & $\begin{array}{l}-3.33 \\
1\end{array}$ & $\begin{array}{l}-3.80 * \\
6\end{array}$ & $-3 \cdot 92 \star$ & $\begin{array}{l}-3.70 * \\
6\end{array}$ \\
\hline $\begin{array}{l}\text { CPI Inflation } \\
\text { Lag }\end{array}$ & $\begin{array}{l}-6.33 * \\
1\end{array}$ & $\begin{array}{l}-3 \cdot 78 * \\
2\end{array}$ & $\begin{array}{l}-4 \cdot 76 \star \\
3\end{array}$ & $\begin{array}{l}-6.48 * \\
1\end{array}$ & $\begin{array}{l}-4.28 * \\
3\end{array}$ & $\begin{array}{l}-6.16 * \\
1\end{array}$ \\
\hline $\begin{array}{l}\text { Unemployment Rate } \\
\text { Lag }\end{array}$ & $\begin{array}{l}-2.49 \\
3\end{array}$ & $\begin{array}{l}-2 \cdot 65 \\
4\end{array}$ & $\begin{array}{l}-2.87 \\
2\end{array}$ & $\begin{array}{l}-2.55 \\
2\end{array}$ & $\begin{array}{l}-2.68 \\
2\end{array}$ & $\begin{array}{l}-2.74 \\
2\end{array}$ \\
\hline
\end{tabular}

WA44444444444444444444444444444444444444444444444444444444444444U

Notes: Each entry is the Augmented Dickey-Fuller test statistic (see text). Lag is the lag order selected by the AIC. * indicates significance at the 5\% marginal significance level, using the finite sample critical values described in Cheung and Lai (1995). 
TABLE 2

COINTEGRATION TEST RESULTS FOR ACTUAL REVISED SERIES

\begin{tabular}{|c|c|c|c|c|}
\hline \multirow[b]{2}{*}{ VARIABLES } & \multicolumn{4}{|c|}{ Forecast Horizon } \\
\hline & $1 Q$ & $2 Q$ & $3 Q$ & $4 \mathrm{Q}$ \\
\hline \multicolumn{5}{|c|}{ 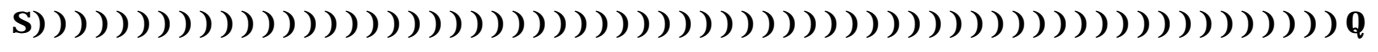 } \\
\hline \multicolumn{5}{|c|}{ Corp. Bond Rate } \\
\hline MAXEIGEN & $21.36(1)$ & $48.38(1)$ & $43.87(1)$ & - \\
\hline trace & $24.62(1)$ & $51.67(1)$ & $46.27(1)$ & - \\
\hline Lag & 2 & 2 & 2 & - \\
\hline RESTRICTION & 1.567 & 1.167 & 2.245 & - \\
\hline \multicolumn{5}{|l|}{ GNP } \\
\hline MAXEIGEN & $11.53(0)$ & $11.16(0)$ & $11.97(0)$ & $40.87(1)$ \\
\hline trace & $18.47(0)$ & $17.58(0)$ & $19.74(1)$ & $47.55(1)$ \\
\hline Lag & 3 & 3 & 4 & 2 \\
\hline RESTRICTION & 0.012 & 0.028 & 1.122 & 0.319 \\
\hline \multicolumn{5}{|l|}{ GNP Deflator } \\
\hline MAXEIGEN & $18.00(1)$ & $12.48(0)$ & $13.33(0)$ & $12.62(0)$ \\
\hline trace & $24.05(1)$ & $18.29(0)$ & $18.71(0)$ & $18.68(0)$ \\
\hline Lag & 4 & 3 & 3 & 4 \\
\hline RESTRICTION & $11.380 *$ & $6.187 \star$ & $7.583 \star$ & $5.798 *$ \\
\hline \multicolumn{5}{|l|}{ Corp. Profits } \\
\hline MAXEIGEN & $7.24(0)$ & $9.19(0)$ & $13.54(0)$ & $13.37(0)$ \\
\hline trace & $11.81(0)$ & $13.61(0)$ & $16.55(0)$ & $15.96(0)$ \\
\hline Lag & 3 & 3 & 2 & 2 \\
\hline RESTRICTION & 0.081 & 0.2479 & 0.004 & 0.058 \\
\hline \multicolumn{5}{|l|}{ Unemployment } \\
\hline MAXEIGEN & $36.19(1)$ & $18.96(1)$ & $16.62(1)$ & $12.23(0)$ \\
\hline trace & $43.54(1)$ & $26.57(1)$ & $22.85(1)$ & $17.82(0)$ \\
\hline Lag & 2 & 3 & 4 & 5 \\
\hline RESTRICTION & 1.643 & 0.296 & 0.377 & 0.635 \\
\hline
\end{tabular}

W444444444444444444444444444444444444444444444444444444444444444U

Notes: MAXEIGEN (trace) indicates the maximal eigenvalue (trace) statistic; the numbers in the parentheses are the implied number of cointegrating vectors using the 5\% marginal significance level and finite sample critical values (Cheung and Lai, 1993). Lag is the lag order selected by the AIC. The critical values for the test on the restriction is 3.84 at the 5\% MSL. * denotes significance at the 5\% MSL . 
TABLE 3

Error Correction Models (Revised Series)

$$
\begin{aligned}
& \Delta x_{t}^{f}=\mu_{1}+\sum_{i=1}^{p} \gamma_{1 i} \Delta x_{t-i}+\sum_{j=1}^{q} \gamma_{2 j} \Delta x_{t-j}^{f}+\alpha_{1}\left(\beta_{1} x+\beta_{2} x^{f}\right)_{t-1}+u_{1 t} \\
& \Delta x_{t}=\mu_{2}+\sum_{k=1}^{r} \gamma_{1 k} \Delta x_{t-k}+\sum_{m=1}^{s} \gamma_{2 m} \Delta x_{t-m}^{f}+\alpha_{2}\left(\beta_{1} x+\beta_{2} x^{f}\right)_{t-1}+u_{2 t}
\end{aligned}
$$

\begin{tabular}{|c|c|c|c|}
\hline \multicolumn{4}{|c|}{ 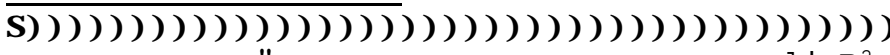 } \\
\hline \multirow{2}{*}{\multicolumn{4}{|c|}{ 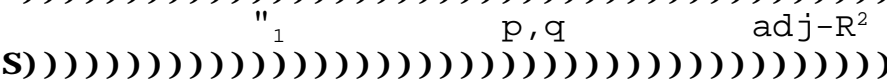 }} \\
\hline & & & \\
\hline \multicolumn{4}{|c|}{ Corporate Bond Rate } \\
\hline$Q=1$ & $0.163 *$ & 0,0 & 0.641 \\
\hline 2 & $0.262 *$ & 0,0 & 6 \\
\hline 3 & $0.196 *$ & 0,1 & \\
\hline
\end{tabular}

PANEL A : FORECASTS

$\begin{array}{cccc}\text { Gross } & \text { National Product } & & \\ \mathrm{Q}=3 & -0.000171 & 4,2 & 0.476 \\ 4 & 0.00491 * & 0,0 & 0.331\end{array}$

Unemployment Rate

$\begin{array}{rlll}Q=1 & 0.070 * & 2,2 & 0.677 \\ 2 & 0.055^{\star} & 2,0 & 0.721 \\ 3 & 0.042^{\star} & 2,2 & 0.499\end{array}$

PANEL B: ACTUAL SERIES

(S) () () () () () ) () () () () )

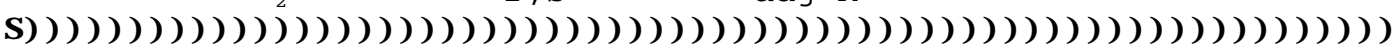

Corporate Bond Rate

$\begin{array}{cccc}\mathrm{Q}=1 & -0.014 & 2,1 & -0.03 \\ 2 & 0.301 & 2,1 & 0.016 \\ 3 & 0.206^{*} & 2,2 & 0.093\end{array}$

Gross National Product

$\mathrm{Q}=3 \begin{array}{cccc}0.00268 * & 0,0 & 0.160 \\ 4 & 0.00294^{*} & 0,4 & 0.191\end{array}$

$\begin{array}{cccc}\text { Unemployment } & \text { Rate } & & \\ \mathrm{Q}=1 & -0.006 & 2,0 & 0.188 \\ 2 & -0.119 * & 2,3 & 0.284 \\ 3 & -0.093 * & 2,2 & 0.302\end{array}$

W4444444444444444444444444444444444444444444444444444444444444444444

Notes: ECT is the error correction coefficient * indicates significance at the 5\% marginal significance level, using heteroskedasticity consistent standard errors. $p, q(r, s)$ is the number of lags in the ECM regressions involving the forecast (actual revised) variables as the dependent variable (see text). All Ljung-Box Qstatistics of order 4 and 8 are not significant at the conventional levels. 
TABLE 4

COINTEGRATION TEST RESULTS FOR ACTUAL UNREVISED SERIES

WA4444444444444444444444444444444444444444444444444444444444444444U

Forecast Horizon

S) ) ()) ) ) ) ) ) ) ) ) ) ) ) ) ) ) ) Q Q

VARIABLES $1 \mathrm{Q} \quad 2 \mathrm{Q} \quad 3 \mathrm{Q} \quad 4 \mathrm{Q}$

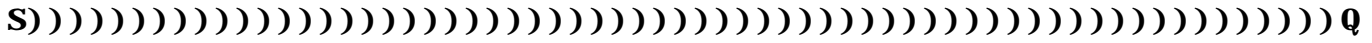

Corp. Bond Rate

MAXEIGEN

trace

Lag

RESTRICTION

GNP

MAXEIGEN

trace

Lag

RESTRICTION

GNP Deflator

MAXEIGEN

trace

Lag

RESTRICTION

Corp. Profits

MAXEIGEN

trace

Lag

RESTRICTION

Housing Starts

MAXEIGEN

trace

Lag

RESTRICTION

$\begin{array}{llll}21.01(1) & 23.48(1) & 61.96(1) & - \\ 25.21(1) & 24.39(1) & 65.76(1) & - \\ 2 & 5 & 2 & - \\ 7.491 * & 8.830 * & 8.677 \star & -\end{array}$

$\begin{array}{llll}22.34(2) & 9.16(0) & 9.57(0) & 20.86(1) \\ 31.73(2) & 17.38(0) & 15.78(0) & 25.20(1) \\ 2 & 3 & 4 & 5 \\ 0.361 & 0.021 & 2.969 & 12.637 \star\end{array}$

$28.31(1) \quad 17.83(1) \quad 15.49(0) \quad 13.95(0)$

$34.13(1) \quad 25.28(1) \quad 25.36(2) \quad 23.34(1)$

$2 \quad 3 \quad 4 \quad 5$

$\begin{array}{llll}1.451 & 1.328 & 0.346 & 2.390\end{array}$

$24.67(1) \quad 26.19(1) \quad 14.52(0) \quad 14.93(0)$

$32.31(1) \quad 33.15(1) \quad 22.46(1) \quad 20.26(0)$

$44 \quad 4 \quad 4 \quad 5$

$\begin{array}{llll}1.903 & 2.526 & 0.076 & 3.307\end{array}$

$27.14(1) \quad 42.64(1) \quad-$

$31.69(1) \quad 46.77(1) \quad-$

$2 \quad 2$

0.3867 .204 * -

Industrial Production MAXEIGEN

trace

Lag

RESTRICTION

$-$

$-$

$-$

$17.52(1)$

21.97 (1)

2

1.722 - 3

$11.60(0)$

$12.41(0)$

3

0.408

Unemployment

$\begin{array}{lllll}\text { MAXEIGEN } & 17.52(1) & 11.52(0) & 7.39(0) & 9.30(0) \\ \text { trace } & 21.97(1) & 18.19(0) & 11.51(0) & 12.95(0) \\ \text { Lag } & 2 & 3 & 4 & 5 \\ \text { RESTRICTION } & 1.722 & 0.283 & 0.002 & 0.024\end{array}$

W44444444444444444444444444444444444444444444444444444444444444U

Notes: MAXEIGEN (trace) indicates the maximal eigenvalue (trace) statistic; the numbers in the parentheses are the implied number of cointegrating vectors using the 5\% MSL and finite sample critical values (Cheung and Lai, 1993). Lag is the lag order selected by the AIC. The critical values for the test on the restriction is 3.84 at the 5\% MSL. * denotes significance at the 5\% MSL. 
TABLE 5

Error Correction Models (Unrevised Series)

$$
\begin{aligned}
& \Delta x_{t}^{f}=\mu_{1}+\sum_{i=1}^{p} \gamma_{1 i} \Delta x_{t-i}+\sum_{j=1}^{q} \gamma_{2 j} \Delta x_{t-j}^{f}+\alpha_{1}\left(\beta_{1} x+\beta_{2} x^{f}\right)_{t-1}+u_{1 t} \\
& \Delta x_{t}=\mu_{2}+\sum_{k=1}^{r} \gamma_{1 k} \Delta x_{t-k}+\sum_{m=1}^{s} \gamma_{2 m} \Delta x_{t-m}^{f}+\alpha_{2}\left(\beta_{1} x+\beta_{2} x^{f}\right)_{t-1}+u_{2 t}
\end{aligned}
$$

PANEL A : FORECASTS

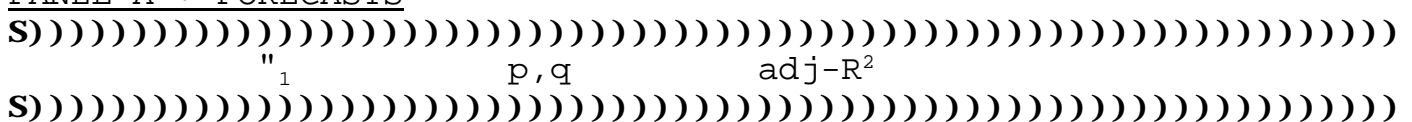

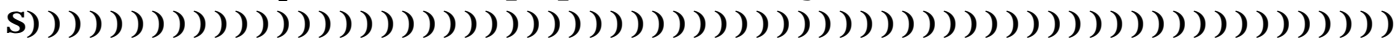

$\begin{array}{cccc}\text { Corporate Bond Rate } & & \\ \mathrm{Q}=1 & 0.207^{*} & 0,2 & 0.583 \\ 2 & 0.096^{*} & 3,0 & 0.800 \\ 3 & 0.526^{*} & 1,1 & 0.807\end{array}$

Gross National Product

$\begin{array}{rrrr}Q=1 & 0.002^{\star} & 1,0 & 0.861 \\ 4 & 0.002^{\star} & 4,2 & 0.734\end{array}$

$\begin{array}{rrrr}\text { GNP } & \text { Deflator } & & \\ \mathrm{Q}=1 & 0.000 & 1,0 & 0.930 \\ 2 & 0.001 & 2,0 & 0.867 \\ 3 & 0.001 * & 3,0 & 0.825 \\ 4 & 0.001 * & 4,0 & 0.795\end{array}$

Corporate Profits after tax

$\begin{array}{llll}Q=1 & -0.001 & 1,0 & 0.09 \\ 2 & 0.017 * & 3,3 & 0.17 \\ 3 & 0.016 & 1,3 & 0.20\end{array}$

Housing Starts
$\mathrm{Q}=1$
0.022
1,0
0.464

Unemployment Rate

$\mathrm{Q}=1$

0.003

2,2

0.59 
PANEL B: ACTUAL SERIES

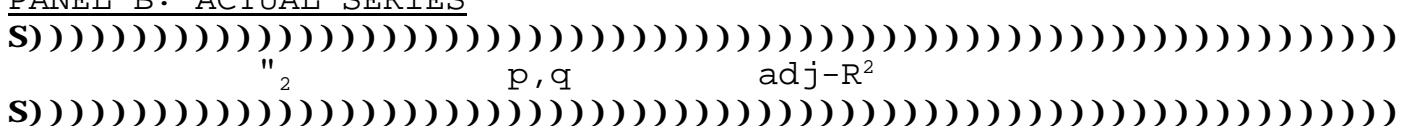

$\begin{array}{cccc}\text { Corporate Bond Rate } & & \\ \mathrm{Q}=1 & 0.085^{*} & 0,2 & 0.046 \\ 2 & 0.038 * & 2,1 & 0.025 \\ 3 & 0.430 * & 2,0 & 0.112\end{array}$

Gross National Product

$\begin{array}{cccc}Q=1 & -0.001^{\star} & 2,1 & 0.101 \\ 4 & -0.001^{\star} & 3,0 & 0.096\end{array}$

$\begin{array}{cccc}\begin{array}{l}\text { GNP } \\ \mathrm{Q}=1\end{array} & \text { Deflator } \\ 2 & -0.002^{*} & 1,0 & 0.614 \\ 3 & 0.000 * & 2,0 & 0.547 \\ 4 & 0.001 * & 1,4 & 0.472 \\ & & \\ \text { Corporate } & \text { Profits after tax } \\ \mathrm{Q}=1 & -0.022^{*} & 1,4 & \\ 2 & -0.002 & 1,1 & 0.573 \\ 3 & -0.028 * & 3,3 & 0.170\end{array}$

Housing Starts

$\mathrm{Q}=1 \quad-0.014 \quad 1,0 \quad 0.001$

Unemployment Rate
$\mathrm{Q}=1$ $-0.247$
1,1
0.114

W444444444444444444444444444444444444444444444444444444444444444444U

Notes: ECT is the error correction coefficient * indicates significance at the 5\% marginal significance level, using heteroskedasticity consistent standard errors. $p, q(r, s)$ is the number of lags in the ECM regressions involving the forecast (actual revised) variables as the dependent variable (see text). All Ljung-Box Qstatistics of order 4 and 8 are not significant at the conventional levels. 
TABLE 6

Comparison of Forecast Response

to Short- and Long-Run Factors (Unrevised Series)

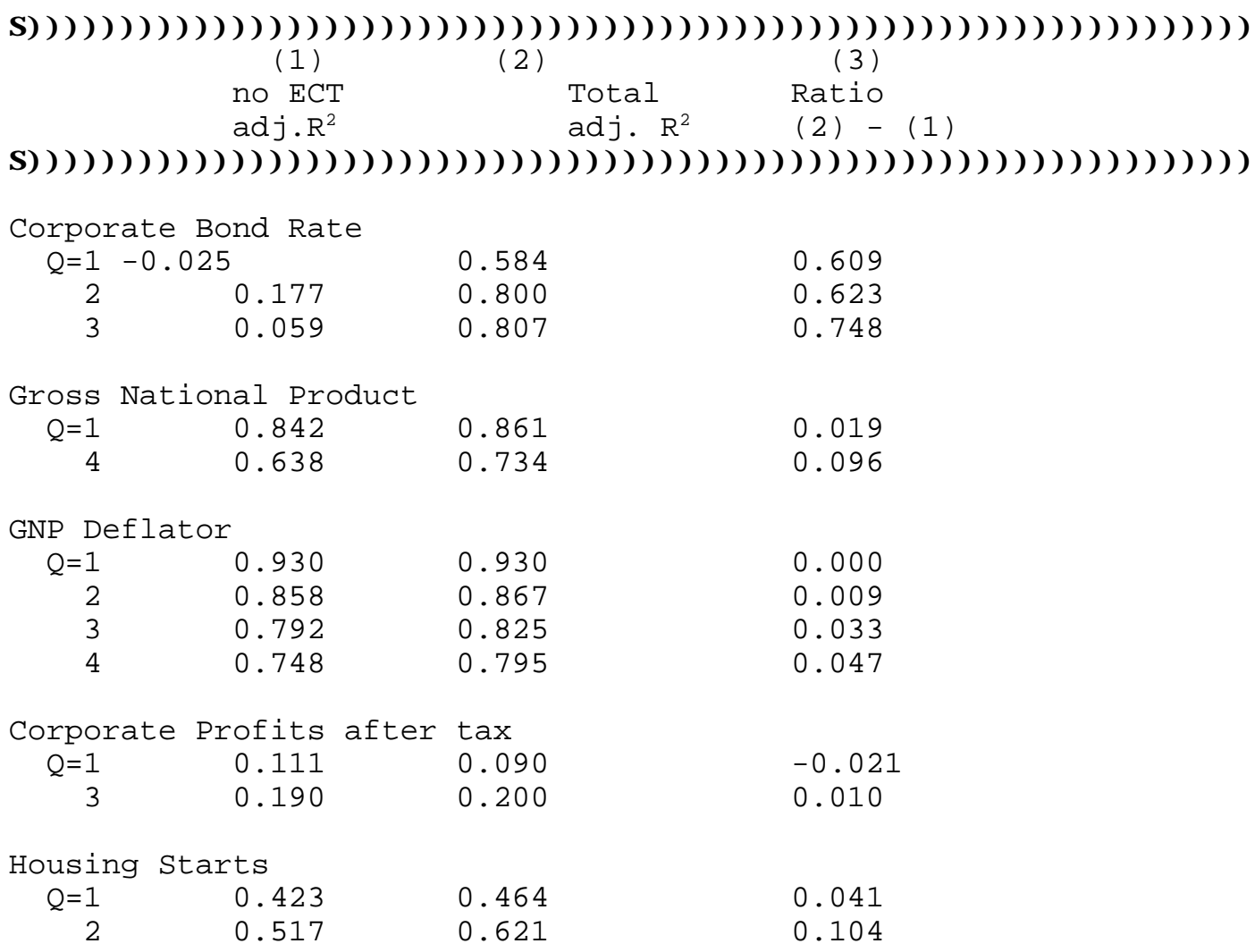

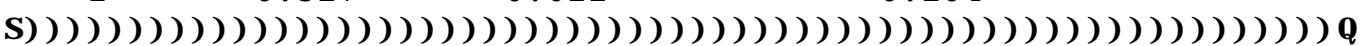

Notes: Each entry is the adjusted- $\mathrm{R}^{2}$ from the error correction model regression with the forecast as the dependent variable. Entries in column (1) are for regressions omitting the error correction term. 
TABLE 7

Summary of Test Results

W4444444444444444444444444444444444444444444444444444444444444444

Panel A: Revised Series

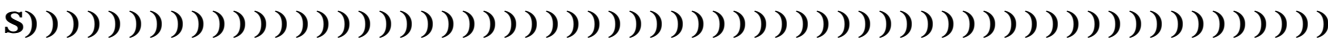

Variables

Forecast Horizon

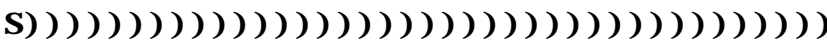

$1 \mathrm{Q} 2 \mathrm{Q} \quad 3 \mathrm{Q} \quad 4 \mathrm{Q}$

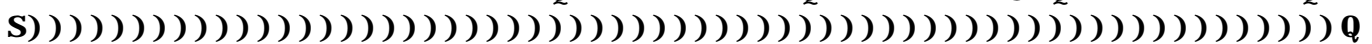

Corporate Bond Rate

Treasury Bill Rate

口ם

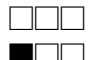

Gross National Product

GNP Deflator

Corp. Profits aftertax

Housing Starts

Industrial Production

CPI Inflation

Unemployment Rate

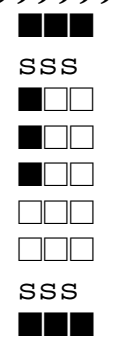

口.

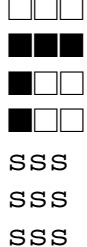

\section{sss}

므
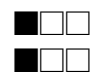

SSS

SSS

SSS

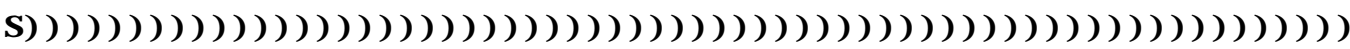
Panel B: Unrevised Series

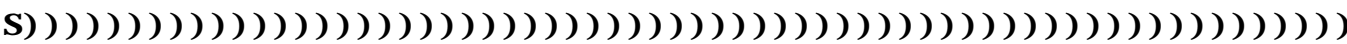
Variables Forecast Horizon

(5) ) () ) ) ) ) () ) ) ) ) ) ) ) ) ) ) ) ) ) ) ) ) ) ) ) ) ) ) ) ) ) )

$\begin{array}{llll}1 \mathrm{Q} & 2 \mathrm{Q} & 3 \mathrm{Q} & 4 \mathrm{Q}\end{array}$

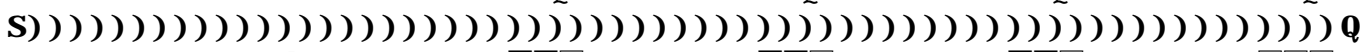

Corporate Bond Rate

Treasury Bill Rate

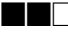

Gross National Product

GNP Deflator

Corp. Profits aftertax

Housing Starts

Industrial Production

CPI Inflation

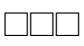

$\square \square$

무

므

SSS

ssin
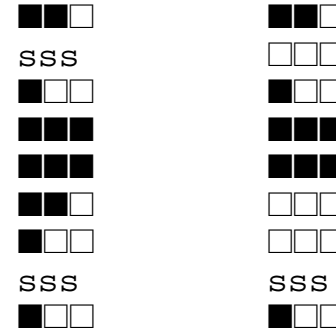

口а

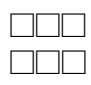

SSS

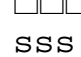

$\square \square \square$

$\square$

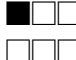

SSS

W44444444444444444444444444444444444444444444444444444444444444444U

Notes: sss indicates both series are trend stationary; $\square \square$ indicates both series are integrated. $\square \square$ indicates series are cointegrated (includes cases where the Maximum Eigenvalue statistic indicates 0 vectors and the trace indicates 1 vector). D indicates series cointegrated, and unitary elasticity restriction is not rejected. 